\title{
Data processing and interpretation of sea radiance factor measurements
}

\author{
HELGI ARST and TIIT KUTSER
}

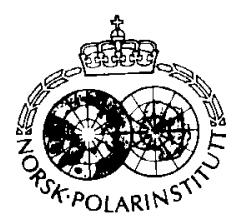

\begin{abstract}
Arst, H. \& Kutser, T. 1994: Data processing and interpretation of sea radiance factor measurements. Polar Research 13, 3-12.

Problems in the interpretation of passive optical remote sensing data obtained by telespectrometric measurements on board a research vessel (or aircraft) are discussed. Two methods are considered: (1) The correlation method, where correlative relationships between the remotely sensed spectra and concentrations of optically active substances in the water are determined and corresponding regression formulae found; (2) the similarity method, where the remotely sensed spectrum is compared with the multitude of spectra obtained by means of model calculations. The application of these methods and analysis of the results are made using our remote and in situ data. It is found that the correlation method is far from being general (the regression parameters depend on the location, season and weather conditions), but it has the advantage of being applicable without the need to describe the aquatic environment by a theoretical model. The similarity method is much more general but involves difficulties in including the optical properties of the aquatic environment in the theoretical model, especially the backscattering properties of several types of suspended matter in the water bodies.

Some aspects of detecting oil-slick pollution on the sea surface by means of passive optical remote sensing methods are discussed and corresponding examples are shown.
\end{abstract}

Helgi Arst and T. Kutser, Estonian Marine Institute, Lai St. 32, Tallinn, EE-OOO1, Estonia.

\section{Introduction}

Throughout the world, passive optical remote sensing from satellites has become one of the main methods of ocean research. It is obvious that for operative information on a global scale the use of satellite measurements is inevitable. However, the interpretation of satellite data is often difficult, not only because of the disturbing influence of the atmosphere and clouds, but also because of some specific features of the objects under investigation. This is particularly noticeable in the case of marginal seas and inland waters, where suspended matter can vary in type and amount over short spatial and temporal scales, concentrations of these substances often being significantly higher than in open ocean waters. Consequently, remote measurements from aircraft, helicopters or ships are also of value and in need of further development. It must also be noted that for the elaboration and application of any remote sensing method, one must proceed through a couple of intermediate stages, where in situ measurements and numerical experiments are made in parallel with remote observations to gather the material to "calibrate" the method and test its efficiency.
In the present paper we consider the passive (the sun being the source of radiation) optical remote sensing method in the case of multicomponental waters. This method represents the following inverse problem: above the water mass under consideration the spectra of the solar radiation reflected from the water surface and backscattered from the water mass are measured by a telespectrometer; on the basis of the numerical values of the results obtained and the characteristics describing the location of extreme values and shapes of these spectra, one tries to estimate the clarity of the water, and the type and amount of optically active substances in the sea. This task is relatively easy if there is only one substance in the water (e.g., phytoplankton). In such a case all the changes in the spectrum of the light backscattered from the water mass into the atmosphere are caused by the absorbing and scattering properties of the water itself and of this single substance. But if there are several optically active substances in the water, their influence on the spectra of the upwelling light is difficult to distinguish. So, in the case of a multicomponental water mass, the task of solving the passive optical remote sensing inverse problem may be com- 
plicated and, in general, an exact and unique solution does not exist. Here it must be emphasized that optical remote sensing always represents an inverse problem, which in most cases is "incorrect" (sensitive to the minor errors in the initial experimental data and having no unique solution). To obtain a unique solution, additional information, and the application of some special mathematical procedures, are needed (Shifrin 1983). For example, it is known that the numerical values of the spectrum of the upwelling light depend rather critically on the total backscattering coefficient of the water environment under consideration. The backscattering coefficient $b^{*}$, in turn, depends on the specific scattering coefficients $\left(b_{i}\right)$, of the substances $(i)$ in the water the concentrations of these substances $\left(C_{i}\right)$ and their backscattering probabilities $\left(\beta_{i}\right)$, i.e. $\mathrm{b}^{*}=\Sigma \beta_{\mathrm{i}} \mathrm{b}_{\mathrm{i}} \mathrm{C}_{\mathrm{i}}$. It is thus clear that several combinations of $\beta_{i}, b_{i}$ and $C_{i}$ may give the same $b^{*}$ and we cannot recreate the values of $C_{i}$ if we know only the product $\beta_{i} b_{i}$; the separate values of $\beta_{i}$ and $b_{i}$ are needed.

In the case of multicomponental waters some other difficulties may arise in determining the type and amount of the optically active substances in the water. For instance, the strong absorption of light by yellow substance overshadows the influence on the spectra of the absorption maximum of chlorophyll $a$ near $440 \mathrm{~nm}$, which complicates the estimation of the chlorophyll concentration from remote sensing data. Consequently, in the case of turbid, multicomponental waters, the problems of interpretation of optical remote sensing data need special attention (the term "interpretation" here meaning the process of estimating the water quality, the type and amount of optically active substances in the water on the basis of optical remote sensing data).

In the case of telespectrometrical measurements directed to the nadir point on board a ship or aircraft, the influence of the air layer between the sea surface and receiver on the measured signal is small and the measured upwelling radiance $L_{u}(\lambda)$ consists of two main components: (1) solar radiance reflected from the wavy sea surface, $L_{R}(\lambda) ;(2)$ solar radiance backscattered from the depths of the water mass, $L_{D}(\lambda)$ :

$$
L_{u}(\lambda)=L_{R}(\lambda)+L_{D}(\lambda)
$$

Here $\lambda$ is the wavelength of light.

The spectra of the component $L_{R}$ give information about the state of the sea surface (undu- lation characteristics, oil slick pollution, etc.) and the spectra of the component $L_{D}$ about the optical characteristics of the water mass (optically active substances in the water).

By means of additional telespectrometrical measurements it is possible to determine separately the value $L_{R}(\lambda)$ and also the radiance factor $r(\lambda)$ (Arst, Pozdnyakov \& Rozenstein 1990):

$$
\mathrm{L}_{\mathrm{R}}(\lambda) \approx 0.02 \mathrm{~L}_{\mathrm{Z}}(\lambda)
$$

Here $L_{z}(\lambda)$ is the spectral radiance of the zenith point of the sky.

$$
\begin{aligned}
r(\lambda) & =\frac{\pi \mathrm{L}_{u}(\lambda)}{\mathrm{E}_{\mathrm{d}}(\lambda)}=\frac{\pi \mathrm{L}_{\mathrm{R}}(\lambda)}{\mathrm{E}_{\mathrm{d}}(\lambda)}+\frac{\pi \mathrm{L}_{\mathrm{D}}(\lambda)}{\mathrm{E}_{\mathrm{d}}(\lambda)} \\
& =\mathrm{r}_{\mathrm{R}}(\lambda)+\mathrm{r}_{\mathrm{D}}(\lambda),
\end{aligned}
$$

where $E_{d}(\lambda)$ is the spectral downwelling irradiance at the sea surface. So, if both $L_{R}$ and $L_{D}$ (and also $E_{d}$ ) are known, it is possible to compute the corresponding components of the radiance factor, $r_{R}(\lambda)$ and $r_{D}(\lambda)$. It must be noted that formula (2) for determining $L_{R}$ gives satisfactory results only in conditions where sun glint does not significantly influence the value of $L_{R}$. If sun glint is significant, the component $L_{R}$ has to be determined by means of more complicated model calculations (Arst, Pozdnyakov \& Rozenstein 1990). Note that if the measurement direction is not far from nadir, the influence of sun glint on $L_{R}$ increases with increasing wind speed and decreasing solar zenith angle. In polar and arctic seas, where the sun is close to the horizon, formula (2) is usually applicable without problems (with the exception of surface pollution by oil or foam).

It must be mentioned that a similar optical inverse problem exists also in the case of underwater optical measurements: determining on the basis of the measured spectra of the attenuation coefficient (or absorption and scattering coefficients) the type and amount of optically active substances, each of them giving a certain contribution to the light attenuation in the water mass under consideration. Here the task is easier in comparison with the remote sensing inverse problem because there is no disturbing "reflected" component, and the information about the backscattering properties is not of great importance.

In the present paper we consider the two interpretation methods for passive optical remote sensing data and demonstrate the corresponding 
results. As shown below, each of these methods has both positive and negative features. In addition, some special problems in the application of passive optical remote sensing for the detection of oil-slick pollution on the sea surface are discussed.

\section{Two methods for the interpretation of passive optical remote sensing data}

As mentioned above we use the term "interpretation" in the sense of the process of obtaining information about the waterbody on the basis of optical remote sensing data. We have avoided the phrase "solution of the optical remote sensing inverse problem" for the reasons described above: there is no exact solution and it may not be unique.

Two methods for the interpretation of the passive optical remote sensing data were considered. The first, the widely used classical method, we named the "correlation method". In this method, a series of telespectrometric observations and simultaneous in situ measurements are made in order to find algorithms connecting the remote sensing and other characteristics of the water (e.g., relative transparency of the water, chlorophyll concentration in the water, etc.). The algorithms are obtained by investigating correlations between the different characteristics. Algorithms obtained by different authors show linear or non-linear interdependence between several characteristics under consideration (Arst, Pozdnyakov \& Rozenstein 1990; Arst et al. 1989; Kirk 1989; Bukata et al. 1991; Carder et al. 1991; Mitchell \& HolmHansen 1991). This kind of investigation involves the problem of how to choose the most suitable characteristics of the remote sensing spectra for the correlation analysis. When the first steps were made in optical remote sensing, optical devices were capable of measuring radiation at $2-4$ wavelengths only. The ratios $r\left(\lambda_{1}\right) / r\left(\lambda_{2}\right)$ (color indices) or combinations of 2-3 color indices were used to seek connections between remote sensing and in situ data. Since then, equipment has improved and it has become possible to measure the full spectrum in the photosynthetically active region (with a spectral resolution of about $5-10 \mathrm{~nm}$ ). In this case one can characterize the shape of the spectra not only by colour indices or other spectral characteristics, but also using integral charac- teristics (Afonin \& Kravtsov 1986; Arst et al. 1990; Kutser et al. 1993). However, as mentioned above, the remote sensing characteristics and corresponding algorithms recommended by different authors are mostly rather dissimilar from each other.

The second, alternative method for the interpretation of optical remote sensing data we call the "similarity method". The basis of this method is the comparison of the measured full spectrum of $r(\lambda)$ (or $r_{D}(\lambda)$ ) with the multitude of the corresponding spectra determined by means of model calculations. From this group of spectra we try to identify the one which is the closest to the experimental spectrum. Thereafter we can determine the concentrations of the optically active substances in the water for the experimental spectrum under consideration, assuming them to be the same as the corresponding initial data for computing the "most similar" theoretical spectrum. Note that for this kind of comparison normalized spectral curves may also be used.

The "similarity" method is not new (e.g., its principal description is presented also in the paper by Lokk \& Purga (1982)), nor is it widely used. The efficiency of this method depends essentially on the validity of the mathematical model describing the spectra of $r(\lambda)$ or $r_{D}(\lambda)$. The principal difficulty is with the detailed description of the absorptive and scattering properties of optically active material in the water (e.g., different types of phytoplankton pigments, organic and inorganic substances, dead and half-dead bluegreen algae, etc.), especially the determination of the backscattering coefficients. Our estimations show that the scattering (and backscattering) coefficients presented in handbooks and monographs (mainly for the open ocean waters) are unsuitable for turbid coastal and inland waters.

We tried to build up a simple model for computing the spectra of $r_{D}$ with the aim of estimating the efficiency of the similarity method on the basis of our remote sensing data. We assumed that there are only three optically active substances in the water: chlorophyll $a$, yellow substance and hydrosol. Under these conditions the total spectral absorption coefficient of the water, $a_{\lambda}$, is described by the following formula:

$$
a_{\lambda}=a_{w, y}+a_{c h l, \lambda} C_{c h l}+a_{y, \lambda} C_{y}+a_{H, \lambda} C_{H},
$$

where $a_{w, \lambda}$ is the spectral absorption coefficient of pure water; $a_{c h l, \lambda}, a_{y, \lambda}, a_{H, \lambda}$ are respectively the spectral specific absorption coefficients of chloro- 
phyll, yellow substance and hydrosol; and $\mathrm{C}_{\mathrm{Ch}}$, $C_{y}$ and $C_{H}$ are their respective concentrations in the water. The values of $a_{w, \lambda}, a_{c h l, \lambda}$ and $a_{H, \lambda}$ were obtained from Plass, Humphreys \& Kattawar (1978) (from which $\mathrm{C}_{\mathrm{Chl}}$ values are obtained in $\mathrm{mg} / \mathrm{m}^{3}$, but $C_{H}$ values only in relative units). The values of $\mathrm{a}_{\mathrm{y}, \lambda}$ were calculated by the formula, taken from Topliss, Miller \& Irvin (1989):

$$
\mathrm{a}_{\mathrm{y}, \lambda}=0.565 \exp [-\gamma(\lambda-380)],
$$

where $\gamma=0.013 \pm 0.005, \lambda$ is given in $\mathrm{nm}$, and $\mathrm{a}_{\mathrm{y} \lambda}$ in $\mathrm{l} \cdot \mathrm{mg}^{-1} \cdot \mathrm{m}^{-1}$. The values of $\mathrm{C}_{\mathrm{y}}$ will be in $\mathrm{mg} / \mathrm{l}$.

The total spectral backscattering coefficient, $b_{\lambda}^{*}$ is given by

$$
\mathrm{b}_{\lambda}^{*}=0.5 \mathrm{~b}_{\mathrm{w}, \lambda}+\beta_{\lambda, \mathrm{H}} \mathrm{b}_{\mathrm{H}} \mathrm{C}_{\mathrm{H}},
$$

where $b_{w, \lambda}$ is the spectral scattering coefficient of the pure water and $b_{H}$ is the specific scattering coefficient of hydrosol. $\beta_{\lambda, \mathrm{H}}$ is the ratio of the hydrosol backscattering coefficient to its scattering coefficient. The values of $b_{H}$ and $\beta_{\lambda . H}$ were estimated from physical models of scattering properties of the seawater by Kopelevich (1983).

On the basis of the values of $a_{\lambda}$ and $b_{\lambda}^{*}$ we can determine the Gordon's parameter $\mathrm{X}_{\lambda}$ (Gordon, Brown \& Jacobs 1975):

$$
\mathrm{X}_{\lambda}=\frac{\mathrm{b}_{\lambda}^{*}}{\mathrm{a}_{\lambda}+\mathrm{b}_{\lambda}^{*}},
$$

which is used in the formulae to calculate the diffuse reflectance of the sea just below $(z=-0)$ and just above $(z=+0)$ the water surface. From Gordon, Brown \& Jacobs (1975):

$$
\begin{aligned}
& r_{D}(z=-0)= \\
& 0.0003+0.3687 X+0.1802 X^{2}+0.0740 X^{3}, \\
& \quad r_{D}(z=+0)=0.179 X+0.051 X^{2}+0.171 X^{3} .
\end{aligned}
$$

Here one can see that

$$
\mathrm{r}_{\mathrm{D}}(\mathrm{z}=+0) \approx 0.5 \mathrm{r}_{\mathrm{D}}(\mathrm{z}=-0),
$$

(see also Arst, Pozdnyakov \& Rozenstein 1990). An alternative formula for computing $r_{D}(z=-0)$ is presented by Kirk (1989):

$$
r_{D}(z=-0)=\left(0.975-0.629 \mu_{0}\right) \frac{b^{*}}{a},
$$

where $\mu_{0}$ is the cosine of the direct solar beam in the water (after refraction).
Taking into account formula (10) we get:

$$
\mathrm{r}_{\mathrm{D}}(\mathrm{z}=+0) \approx 0.5\left[\left(0.975-0.629 \mu_{0}\right) \frac{\mathrm{b}^{*}}{\mathrm{a}}\right] \text {. }
$$

Using formulae (4)-(6) and (12) a program was developed to calculate the model spectra of $r_{D}$ and compare these with the measured spectra. Naturally, we did not expect to get the $100 \%$ coincidence, because our model is not ideal and the absolutely correct experimental spectra are unreal. For this reason we considered in each case ten "model" spectra, most similar to the experimental one.

\section{Results and discussion}

To estimate the efficiency of any method for the interpretation of remote sensing data, simultaneous remote and in situ measurements must be carried out. After data-processing one can compare the results obtained from the water samples with those from the remote sensing method. Since 1981 we have made several expeditions in the Baltic Sea and in Estonian lakes at which telespectrometrical and in situ measurements were carried out mainly on board a ship. Considering the correlation method, we have investigated the appropriateness of 20 spectral and 6 integral characteristics for the interpretation of remote measurement data (Arst, Eerme \& Purga 1984; Arst et al. 1989; Arst et al. 1990; Kutser et al. 1993). Using correlative relationships between these characteristics and the results of in situ measurements in the waterbody, we have determined several algorithms to compute the relative (Secchi disk) transparency and the chlorophyll $a$ concentration in the water from the telespectrometrical data.

As an example of these results we present the algorithm for the chlorophyll concentration $\left(\mathrm{C}_{\mathrm{Ch}}\right)$ using data obtained from the Gotland Deep polygon (in the Baltic Sea) in summer 1989 (corresponding correlation coefficient $R=0.84$ ):

$$
\mathrm{C}_{\text {chl }}=5.2 \mathrm{Y}-1.53 \text {. }
$$

Here

$$
Y=\frac{\int_{415}^{455} r_{D}(\lambda) d \lambda \times \int_{655}^{690} r_{D}(\lambda) d \lambda}{\int_{465}^{605} r_{D}(\lambda) d \lambda},
$$


where the bounds of the integrals are the wavelengths of light in $\mathrm{nm}$.

The isolines of the chlorophyll concentrations measured and calculated by formula (13) are shown in Fig. 1. These isolines match rather well. However, our investigations in other regions of the Baltic give different results. For instance, in the polygons of the Gulf of Finland the chlorophyll concentration has a poor correlation $(R=$ 0.33 ) with $\mathrm{Y}$, but a good correlation $(\mathrm{R}=0.72-$ 0.82 ) with several other characteristics of the remote sensing spectra (mostly with the spectral differences of radiance factor).

Similar results were obtained from the largest Estonian lake, Lake Peipsi. In Fig. 2 the isolines of the Secchi disk transparency (SD), determined by remote sensing and in situ methods from an

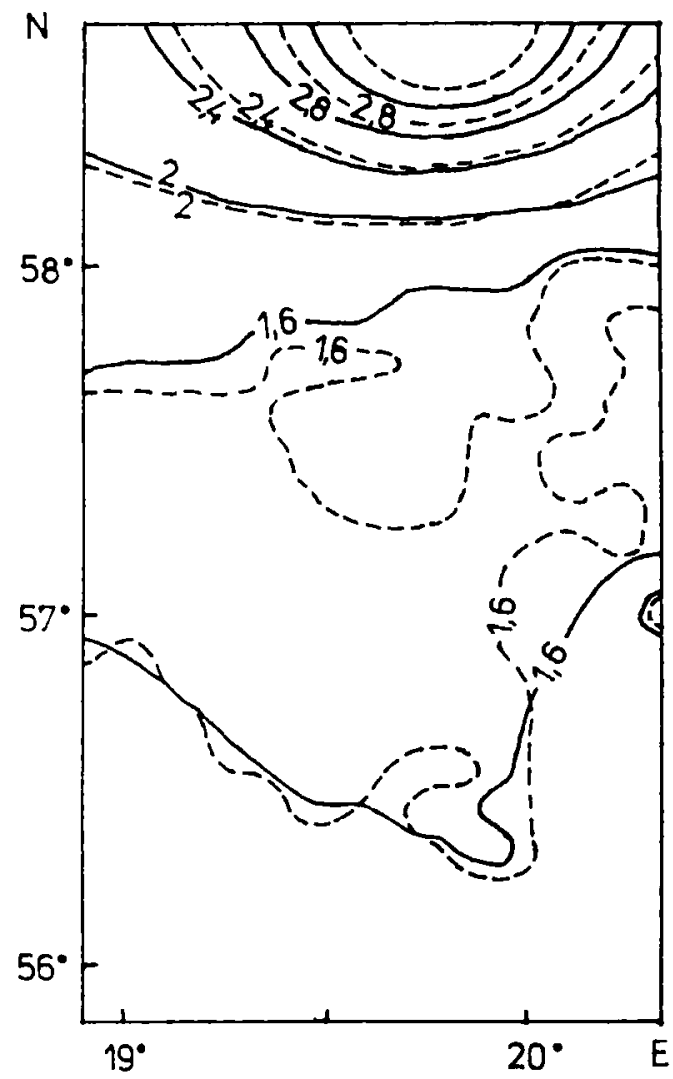

Fig. 1. Estimation of the chlorophyll $a$ concentration by telespectrometric measurements in a polygon at Gotland Deep (Baltic Sea) 30 June-1 July 1989. Solid and dashed lines indicate respectively the $C_{c h l}$ isolines, measured in situ and computed using formulae (13) and (14).

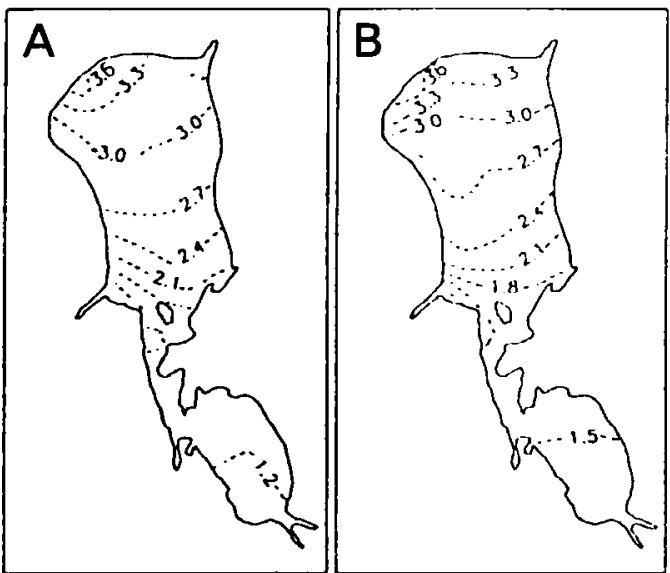

Fig. 2. Isolines of the Secchi disc depth in Lake Peipsi on 13 June 1987 measured in situ (A) and calculated from remote sensing results (B) using formulae (15) and (16). The corresponding correlation coefficient is 0.96 .

expedition in June 1987 are presented. The corresponding algorithm is

$$
\mathrm{SD}=16.4 \mathrm{~W}\left(\mathrm{~L}_{\mathrm{u}}\right)+0.45 \text {. }
$$

Here

$$
W=\frac{L_{u}(530)-L_{u}(600)}{L_{u}(600)},
$$

and $L_{u}(\lambda)$ is the value of the upwelling radiance at the wavelength of light $\lambda$ (direction of measurements is to nadir, $\lambda$ is in $\mathrm{nm}$ ).

However, a good fit between the remote sensing data and the in situ measurements, such as Fig. 2, can be obtained only by relying on the results of a single expedition. Our attempts to determine a general algorithm, using the whole data set (for Lake Peipsi there were four expeditions in different weather conditions) were unsuccessful. Neither did we succeed in finding among the whole range of characteristics of the remote sensing spectra a single preferred characteristic for describing water quality. Though undeniably there do exist connections between the optical remote sensing data and several substances in the water, it seems there is no universal algorithm determined by the correlation method, which can describe these connections for different water bodies and in different weather conditions. This conclusion is supported by the results of other researchers (Højerslev \& Jerlov 1977; Büttner \& Vörös 1981; Aarup et al. 1990; Bukata et al. 1991; Mitchell \& Holm-Hansen 1991). 
An attempt to estimate the efficiency of the similarity method was made using telespectrometric data and simultaneously measured chlorophyll concentrations from 87 sampling stations in the Baltic Sea and some Estonian lakes. The measured chlorophyll $a$ concentration varied between 0.3 and $47 \mathrm{mg} / \mathrm{m}^{3}$. Unfortunately we were not able to obtain values of $C_{y}$ and $C_{H}$. However, the results obtained are quite interesting. It appears that the divergence of the values of $\mathrm{C}_{\mathrm{Ch}}, \mathrm{C}_{\mathrm{y}}$ and $\mathrm{C}_{\mathrm{H}}$ corresponding to the ten "most similar" theoretical spectra is relatively small (there are several combinations of $\mathrm{C}_{\mathrm{Chl}}, \mathrm{C}_{\mathrm{y}}$ and $\mathrm{C}_{\mathrm{H}}$ for which some numerical values are identical and some differ by not more than one or two grid steps in the values put into the model). Consequently, we obtain rather stable final results by averaging these ten values. It is worth noting that in most cases the best results give the normalized spectra (in our calculations the normalizing wavelength is $520 \mathrm{~nm}$ ).

The correlation coefficient between the computed and measured chlorophyll concentration values is 0.82 . If the measured $C_{C h l}$ is between 0.3 and $4 \mathrm{mg} / \mathrm{m}^{3}$, the corresponding computed $\mathrm{C}_{\mathrm{Ch}}$ is between the same limits, but the relative error is often high. Here the influence of chlorophyll on the radiance factor spectra is often screened by the stronger influence of the yellow substance and hydrosol, which have high concentrations in turbid waters. As a rule, the relative difference between measured and calculated $C_{c h l}$ values decreases with increasing chlorophyll concentration. For the whole data set, the computed values of yellow substance and hydrosol concentrations vary from 0.1 to $16 \mathrm{mg} / \mathrm{l}$ and from 1 to 40 correspondingly.

In Fig. 3 two examples of the $r_{D}$ spectra obtained from telespectrometrical measurements, and the corresponding "most similar" model spectra, are shown. Note that we took these results from the group of spectra which gave very good coincidence between the measured and calculated chlorophyll concentrations.

We had no telespectrometrical data for the waters of the cold regions (including the Arctic and Antarctic). However, one can assume that in these waters the yellow substance and hydrosol concentrations are significantly lower than in the lakes and coastal waters in moderate latitudes. We made computations using the similarity model for underwater data (the values of $c_{\lambda}=a_{\lambda}+b_{\lambda}$ are necessary) from moderate and cold regions.

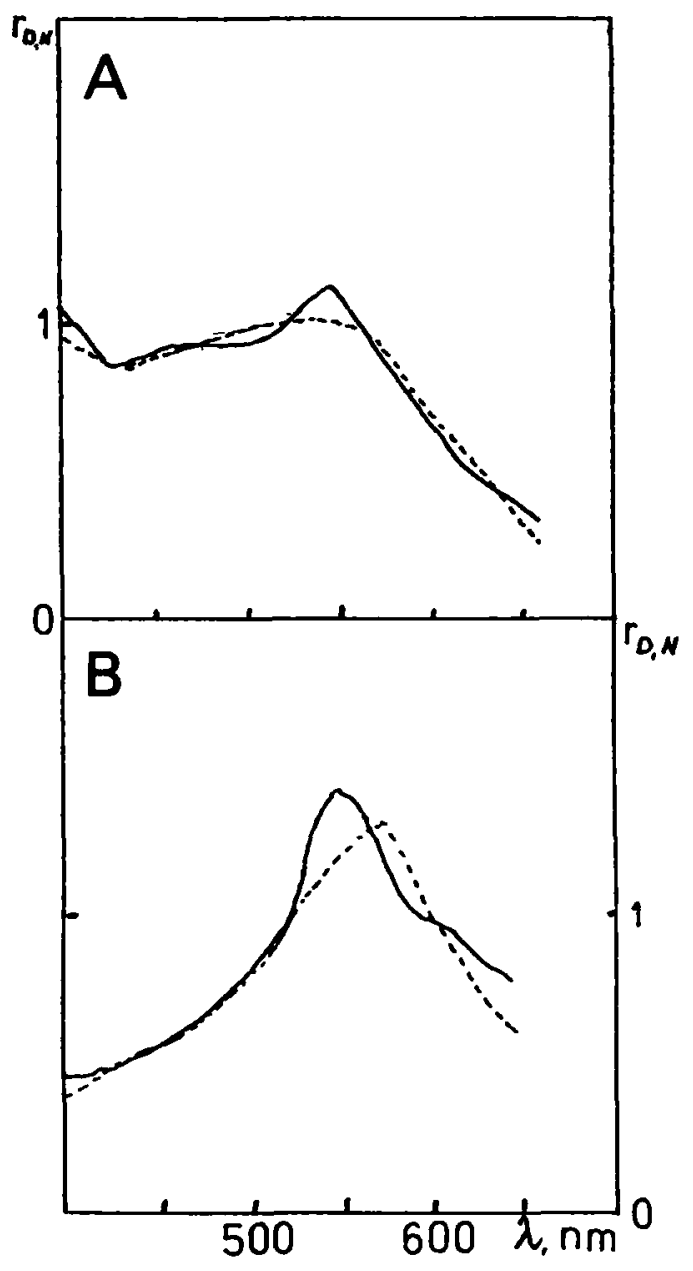

Fig. 3. Comparison of the $r_{D N}$ (normalized $r_{D}$ ) spectra obtained on the basis of the telespectrometrical measurements (solid curves) with those determined as the "most similar" by model calculations (dashed curves): A. the Baltic Sea, near Bornholm Island, 27 July 1981; B. Estonia, Lake Peipsi, 14 August 1990. The $\mathrm{C}_{\mathrm{chl}}$ values determined from water samples arc respectively 2.2 and $8.7 \mathrm{mg} / \mathrm{m}^{3}$, the "modcl spectra" give the following results: $C_{\text {chl }}=2.0 \mathrm{mg} / \mathrm{m}^{3}, C_{y}=0.4 \mathrm{mg} / \mathrm{l}$ (Bornholm waters) and $\mathrm{C}_{\mathrm{chl}}=7.3, \mathrm{C}_{\mathrm{y}}=12.0$ (Lake Peipsi).

In the first case the values of $c_{\lambda}$, determined by us for Pärnu Bay in April 1993, were used. In the second case we used the data by Matsuike, Nakamura \& Hago (1979) for the Bering Sea in July and August. Unfortunately, in this paper only data on the irradiance attenuation coefficients were presented and we had to determine the necessary values of $a_{\lambda}$ using the formula by Kirk (1989) describing the relationship between 
absorption coefficient, scattering coefficient and irradiance attenuation coefficient. The spectral values of the scattering coefficient we took from the data of scattering model 2 by Kopelevich (1983) (scattering coefficient at $400 \mathrm{~nm}$ is $0.087 \mathrm{~m}^{-1}$ and decreases down to $0.049 \mathrm{~m}^{-1}$ ) at $680 \mathrm{~nm}$. Some examples of the results of these calculations are presented in Table 1. As expected, the concentrations of optically active substances in the highly turbid waters of Pärnu Bay significantly exceed those in the Bering Sea. For Pärnu Bay we have also determined the corresponding values of chlorophyll and yellow substance concentrations from water samples. These values are mostly close to those calculated on the basis of beam attenuation coefficient spectra. As mentioned above there are difficulties of determining the $\mathrm{C}_{\mathrm{chl}}$ values in turbid waters, containing high amount of yellow substance. Obviously this is the reason for the comparatively poor coincidence of the $C_{c h l}$ values at Pärnu Bay Station 9.

Table 1. Values of the irradiance attenuation coefficient (in $\mathrm{m}^{-1}$ ) for stations 4 and 11 in the Bering Sea (data taken from Matsuike et al. 1979), the beam attenuation coefficient (in $\mathrm{m}^{-1}$ ) for stations 9 and 11 in the Pärnu Bay (our measurements in April 1993) and concentrations of $\mathrm{C}_{\text {chl }}$ (in $\mathrm{mg} / \mathrm{m}^{3}$ ), $\mathrm{C}_{\mathrm{y}}$ (in $\mathrm{mg} / \mathrm{l}$ ) and $C_{H}$ (in relative units) calculated on the basis of these spectra. For Pärnu Bay the corresponding values $\mathrm{C}_{\mathrm{chl}}$ and $\mathrm{C}_{\mathrm{y}}$, determined from water samples, are also shown.

\begin{tabular}{|c|c|c|c|c|c|}
\hline \multicolumn{3}{|c|}{ Bering Sea } & \multicolumn{3}{|c|}{ Pärnu Bay } \\
\hline$\lambda, \mathrm{nm}$ & St. 4 & St. 11 & $\lambda, \mathrm{nm}$ & St. 9 & St. 11 \\
\hline 375 & 0.16 & 0.36 & 400 & 12.32 & 9.40 \\
\hline 427 & 0.14 & 0.39 & 420 & 10.22 & 8.49 \\
\hline 484 & 0.078 & 0.30 & 450 & 7.89 & 7.33 \\
\hline 513 & 0.098 & 0.24 & 480 & 6.60 & 6.68 \\
\hline$\$ 72$ & 0.13 & 0.17 & 500 & 5.89 & 6.32 \\
\hline 622 & 0.38 & 0.39 & 520 & 5.52 & 6.10 \\
\hline 650 & 0.42 & 0.49 & 550 & 5.05 & 5.94 \\
\hline \multirow[t]{3}{*}{681} & 0.53 & 0.54 & 580 & 4.84 & 5.67 \\
\hline & & & 600 & 4.64 & 5.59 \\
\hline & & & 650 & 4.31 & 5.52 \\
\hline
\end{tabular}

Calculated from underwater optical data

\begin{tabular}{llrrr}
\hline $\mathrm{C}_{\mathrm{chl}}$ & 0.3 & 1.2 & 8 & 4 \\
$\mathrm{C}_{\mathrm{y}}$ & 0.1 & 0.2 & 18 & 7 \\
$\mathrm{C}_{\mathrm{H}}$ & 1.0 & 4.5 & 70 & 65 \\
\hline
\end{tabular}

Measured from water samples

\begin{tabular}{lllll}
\hline $\mathrm{C}_{\text {chl }}$ & - & - & 12.4 & 5.2 \\
$\mathrm{C}_{\mathrm{y}}$ & - & - & 19.5 & 8.2 \\
\hline
\end{tabular}

The tests for estimating the efficiency of the similarity method indubitably need to be continued using additional (and larger) data sets and an improved computation model. However, our preliminary results show that this method is quite promising.

\section{Detection of oil-slick pollution on the sea surface}

The spectra of the radiation factor component $r_{R}(\lambda)$, obtained from passive optical remote measurements enable the detection of oil-slick pollution on the water surface (Arst, Pozdnyakov \& Rozenstein 1990). As is well known, the light reflection coefficient of the oil exceeds that of the water; for that reason one can expect a positive contrast between $r_{R}$ (oil) and $r_{R}$ (water). At the same time the oil-slick pollution changes the surface wave characteristics. For the latter reason the contrast between the $r_{R}$ values for pure and oil-polluted sea surfaces depends on the measurement direction, solar zenith angle, wind speed and direction, angle between wind direction and sun's azimuth. The model computations on the basis of formulae, taken from Arst, Pozdnyakov \& Rosenstein (1990), show that under conditions of an undulating sea surface, "abnormal" contrasts may occur in which the $r_{R}$ values for the pure water surface exceed the corresponding $r_{R}$ values for the oil-polluted sea surface. Some examples of the dependence of $r_{R}$ on wind velocity for the cases of polluted and clean sea surfaces, and observations at nadir, are shown in Fig. 4. As one may see the variability of the positive and negative values of the difference $\Delta r_{R}=$ $r_{R}$ (oil) $-r_{R}$ (water) depends on the solar zenith angle. Computations of $\Delta r_{R}$ for several measurement directions show that the character of its variability is rather irregular. The influence of the oil-slick on the $r_{R}$ values is most conveniently demonstrated by means of the contrast $K=\Delta r_{R} /$ $r_{R}$ (water). Some examples of the variability of this contrast for light and heavy Baku oil are shown in Fig. 5. As one may see, for wind speed $5 \mathrm{~m} / \mathrm{s}$, solar zenith angle $30^{\circ}$ and measurement direction to nadir, $K$ is negative and its absolute value is small; oil-slick detection is easiest when the nadir angle is about $15-45^{\circ}$ and the azimuth of measurement is $180^{\circ}$. But in the case $\vartheta_{0}>60^{\circ}$ (typical for the northern seas) and wind velocity 

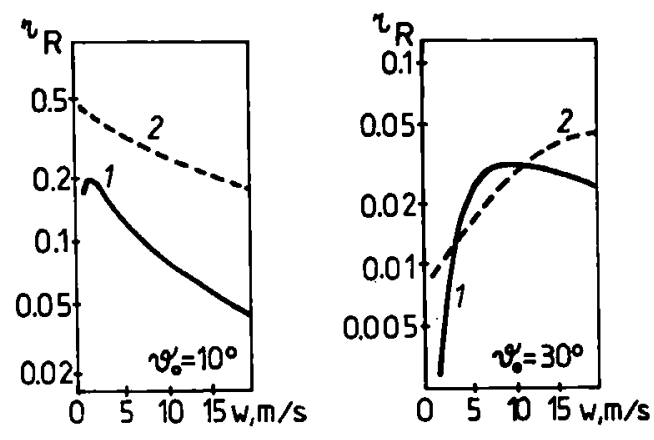

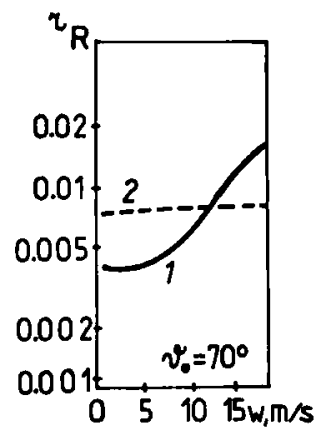

Fig. 4. Dependence of the component $r_{R}$ on the wind velocity ( $w$ ) and the solar zenith angle $\left(\vartheta_{0}\right)$ for a slick of heavy Baku oil (dashed curves) and pure water (solid curves). The thickness of the oil slick is $50 \mu \mathrm{m}$, the wavelength of light $720 \mathrm{~nm}$, the measurement direction is to nadir, the azimuth of wind and the sun are the same.
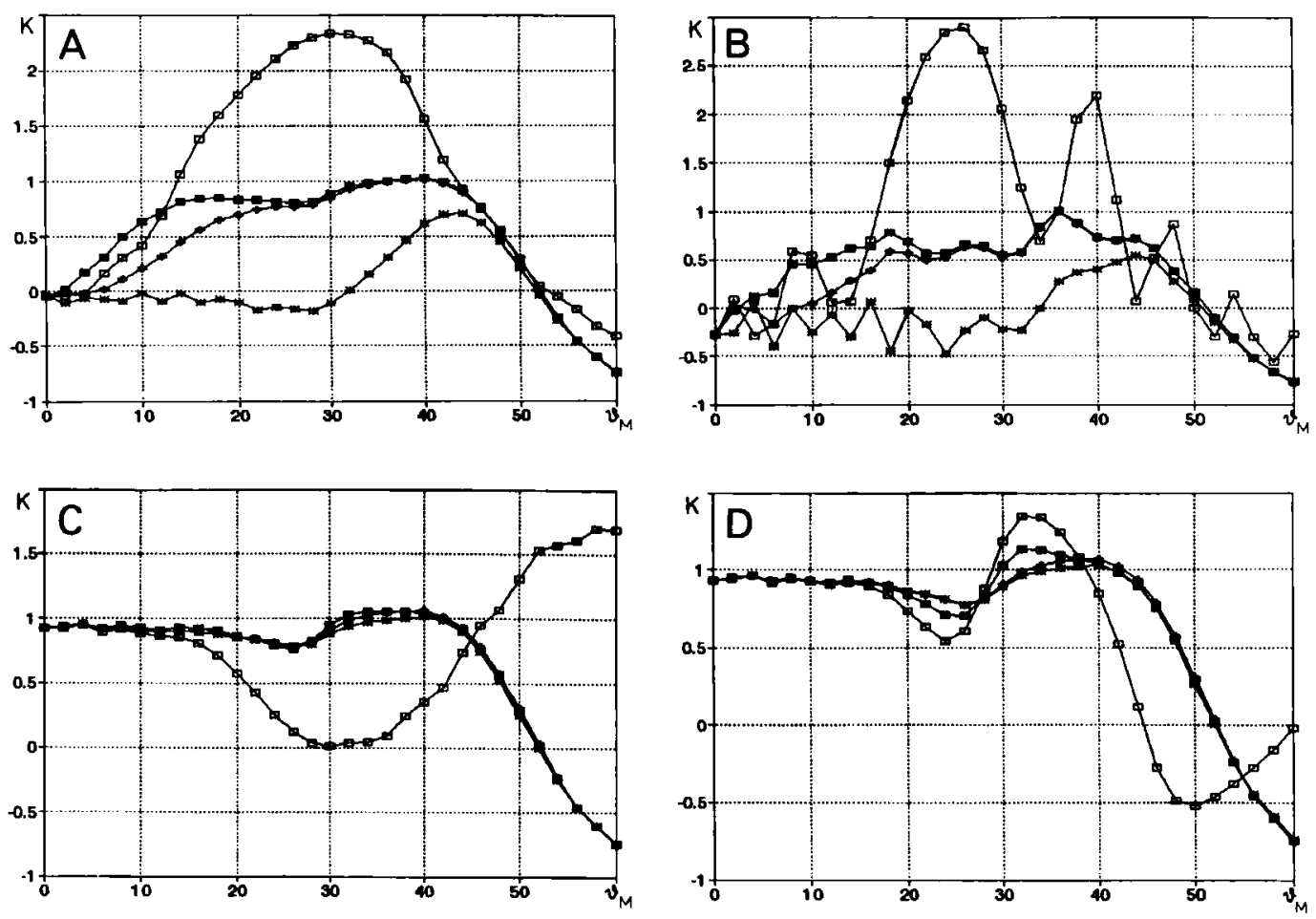

Fig. 5. Dependence of the contrast $\mathrm{K}$ on the measurement direction (azimuth $\alpha_{\mathrm{M}}$ and zenith angle $\vartheta_{\mathrm{M}}$ ) and solar zenith angle $\vartheta_{0}$ (wind velocity $5 \mathrm{~m} / \mathrm{s}$, wind direction $\alpha_{M}=45^{\circ}$, sun's azimuth $\alpha_{M}=0^{\circ}$ ) for wavelength of light $510 \mathrm{~nm}$ and oil slick thickness $50 \mu \mathrm{m}$. The values of $\alpha_{M}$ are shown by the following: $0^{\circ}$ (filled square), $60^{\circ}$ (plus), $120^{\circ}$ (asterisk) and $180^{\circ}$ (empty square), A, C, D = heavy Baku oil, $\vartheta_{0}$ is $30^{\circ}, 60^{\circ}$ and $80^{\circ}$, respectively; $\mathrm{B}=$ light Baku oil, $\vartheta_{0}$ is $30^{\circ}$.

$\mathrm{w}<7 \mathrm{~m} / \mathrm{s}$, measurement directions near to nadir are most suitable for the detection of the oil slick on the sea. Here the further increase of the wind velocity causes a decrease of $\Delta r_{R}$ (through zero to negative values). However, under conditions of strong wind the oil slick is usually torn and the determination of the contribution of oil to the $r_{R}$ values is complicated.

Note that due to light interference phenomena in the oil-slick the curves of $r_{R}$ and $K$ often have an oscillating character (for example, the curves for light Baku oil in Fig. 5). The period and 
amplitude of this oscillation depend on the wavelength of light, the thickness of the oil slick and on the type of oil. In the case of oscillations within a small period, the grid step in the computation procedure must be very small, otherwise the shape of the $r_{R}$ (or $K$ ) curves cannot be accurately described.

\section{Conclusions}

The main conclusions of the preliminary investigations of two methods for the interpretation of passive optical remote sensing data are charted below.

Both the methods under consideration need accurate telespectrometrical data. Here, as was mentioned above, the main source of instability is the influence of sun glint on the values of $r_{R}(\lambda)$.
To avoid this, a suitable measurement direction must be chosen; however, in many cases the nadir direction is technically the most suitable. In this case measurements in conditions of great solar zenith angles guarantees that the results are free from the influence of sun glint, but in these conditions the solar radiation reflected from the nadir point is small and an apparatus with high sensitivity is required.

It is quite possible to detect oil-slick pollution using passive optical remote sensing method, but because of the instability of the contrast between $r_{R}$ (oil) and $r_{R}$ (water) the interpretation of the results has to be performed by numerical modelling.

Acknowledgements. - The authors express their gratitude to T. Miller and L. Käärmann for their help in carrying out the work.

\section{Comparison of the correlation and similarity methods}

Method Positive Negative

Correlation method, where correlative relationships between the spectra of $r(\lambda)$ (or $\left.r_{D}(\lambda)\right)$ and concentrations of optically active substances in water are determined and corresponding regression formulae found.

Similarity method, where the spectra of $r(\lambda)$ (or $r_{D}(\lambda)$ ) are compared with the multitude of spectra obtained from model calculations to find the theoretical spectrum which is closest to experimental. It is assumed that the concentrations of substances used for computing the theoretical spectrum are the same for the experimental spectrum.
No need to describe the water environment by a theoretical model, only experimental data for the determination of the regression formulae are necessary.

Considerably more general than the correlation method. If the theoretical model is successful, the similarity method works everywhere.
The parameters of the regression formulae depend on the location, season and weather conditions. Not general.
There are difficulties in the detailed description of the absorbing and scattering properties of all the optically active substances, especially the type, size distribution and backscattering properties of suspended matter in the computation model. 


\section{References}

Aarup, T., Groom, S. \& Holligan, P. M. 1990: The processing and interpretation of North Sea CZCS imagery. Netherlands J. Sea Res. 25, 3-9.

Afonin, E. \& Kravtsov, G. 1986: Modern apparatus and methods of the ocean and atmosphere in visible part of light spectrum. Sevastopol. 75 pp. (in Russian).

Arst, H., Eerme, K. \& Purga, A. 1984: On the brightness coefficient of the Baltic Sea. Deutsche Hydrogr. Zeitschr. 37 (H6), 221-233.

Arst, H., Miller, T., Torp, T., Lukk, T. \& Meitern, J. 1989: Estimation of the Transparency of the Baltic Sea waters and Estonian lakes by optical remote measurements. Proc. 16th Conf. Baltic Oceanographers, Kiel, 711-716.

Arst, H., Käärmann, L., Miller, T., Torp, T. \& Kutser, T. 1990: Estimation of the Baltic Sea water quality by optical remote measurements. Abstracts 17th Conf. Baltic Oceanographers, Norrköping, Sweden.

Arst, H., Pozdnyakov, D. \& Rozenstein, A. 1990: Optical remote sensing in oceanography. Valgus, Tallinn. $444 \mathrm{pp}$. (in Russian).

Büttner, O.\& Vörös, L. 1981: Investigation of Hungarian lakes by means of Landsat data. Adv. Space. Res. 1, 177-189.

Bukata, R. P., Jerome, J. H., Kondratyev, K. Y. \& Pozdnyakov, D. V. 1991: Satellite monitoring of opticallyactive components of inland waters: an essential input to regional climate change impact studies. J. Great Lakes Res. $17,470-478$.

Carder, K. L., Hawes, S. K., Baker, K. A., Smith, R. C., Steward, R. G. \& Mitchell, B. G. 1991: Reflectance model for quantifying chlorophyll $a$ in the presence of productivity degradation products. J. Geophys. Res. 96 (C11), 20,59920,611 .
Gordon, H. R., Brown, O. B. \& Jacobs, M. M. 1975: Computed relationships between the inherent and apparent optical properties of a flat homogenous ocean. Appl. Opt. 14, 417427.

Højerslev, N. \& Jerlov, N. 1977: The use of the color index for determining quanta irradiance in the sea. Rep. Inst. Phys. Oceanogr., Copenhagen University, No. $35.12 \mathrm{pp}$.

Kirk, J. T. O. 1989: The assessment and prediction of optical water quality. Australian Water and Wastewater Association J3th Federal Convention, 504-507.

Kopelevich, O. V. 1983: Few-parameter model of the optical properties of the seawater. Pp. 208-235 in Monin, A. S. (ed.): Optics of the ocean, Vol. 1. Nauka, Moscow (in Russian).

Kutser, T., Arst, H., Miller, T., Käärmann, L. \& Milius A. 1993: Telespectrometrical estimation of water transparency, chlorophyll $a$ and total phosphorus concentrations on Lake Peipsi (in press).

Lokk, J. \& Purga, A. 1982: Water quality study of the Baltic Sea by optical remote sensing methods. Pp. 523-530 in Hydrodynamics of semienclosed seas. Amsterdam, Elsevier.

Mitchell, B. G. \& Holm-Hansen, O. 1991: Bio-optical properties of Antarctic Peninsula waters: differentiation from temperate ocean models. Deep-Sea Res. 38, 1009-1028.

Matsuike, K., Nakamura, Y. \& Haga, M. 1979: Aerial and submarine spectral solar energy distributions and optical characteristics of the waters in the Bering Sea during the summer. La Mer 17, 1-10.

Plass, G. N., Humphreys, T. J. \& Kattawar, G. W. 1978: Color of the Ocean. Appl. Opt. 17, 1432-1446.

Shifrin, K. S. 1983: Introduction to ocean optics. Gidrometeoizdat, Leningrad. $278 \mathrm{pp}$. (in Russian).

Topliss, G. N., Miller, J. R. \& Irvin, B. 1989: Ocean optical measurements -1 . Statistical analysis of data from the western North Atlantic. Contin. Shelf. Res. 9, 113-131. 